\section{EMBRYRIDDLE}

Aeronautical University

SCHOLARLY COMMONS
Journal of Aviation/Aerospace

Education \& Research

Volume 29

Number 3 JAAER 2020

Article 4

2020

\title{
Configuration Management Challenges of Model Based Systems Engineering on Multiple Variant Aircraft Fleets
}

David R. Zubowski

Embry-Riddle Aeronautical University, dzubowski@gmail.com

Follow this and additional works at: https://commons.erau.edu/jaaer

Part of the Systems Engineering and Multidisciplinary Design Optimization Commons

\section{Scholarly Commons Citation}

Zubowski, D. R. (2020). Configuration Management Challenges of Model Based Systems Engineering on Multiple Variant Aircraft Fleets. Journal of Aviation/Aerospace Education \& Research, 29(3).

https://doi.org/10.15394/jaaer.2020.1871

This Article is brought to you for free and open access by the Journals at Scholarly Commons. It has been accepted for inclusion in Journal of Aviation/Aerospace Education \& Research by an authorized administrator of Scholarly Commons. For more information, please contact commons@erau.edu. 


\section{Introduction}

Since production began in 2004, the United States Marine Corps (USMC) variant of the V-22 Osprey (MV-22) has had many capability and reliability improvements applied to it through approved change management processes while being governed by a Systems Engineering Management Plan (SEMP). Unfortunately, multiple changes during a long production run have resulted in many different configurations, and many times in the same aircraft squadron. The different configurations require different spare parts, have cockpit switches in different places, and have different safety capabilities, such as a traffic collision avoidance system and weather radar. This has led to problems with MV-22 Configuration Management (CM) for the USMC, ranging from ensuring maintenance personnel are using the appropriate variant specific manuals, recognizing the supply costs of stocking spare parts for each variant, and ensuring future modifications are compatible with each targeted variant (Eckstein, 2017). As systems become more complex, CM becomes more important as the means to control what the definition of the system is and manage the changes to that definition (Whyte, Stasis, \& Lindkvist, 2016). Naval Air Systems Command (NAVAIR) is moving from traditional Systems Engineering (SE), focusing on managing documentation, to Model Based Systems Engineering (MBSE), focusing on a system model (All Partners Access Network, n.d.). Working on a model to simulate systems working together that is not representative of all variants could result in the further divergence from the current production definition and the unintentional creation of more variants in the MV-22 fleet.

\section{Background}

The challenge of managing all MV-22 configurations across the globe led NAVAIR to award Boeing a modification to a current contract to upgrade all Block B variants of the MV-22 
to Block C (Boeing, 2018). This award of nearly $\$ 70$ million is to support the MV-22 Common Configuration-Readiness and Modernization (CC-RAM) Program as a cornerstone of the sustainment and affordability of the MV-22 for the remainder of the aircraft life cycle (Boeing, 2018). The CC-RAM program will modify 130 aircraft, each taking between eight and twelve months to complete, to create a common configuration of Block C aircraft (Eckstein, 2017).

However, the MV-22 was managed using a SEMP created with traditional SE techniques of documenting system requirements. As NAVAIR transitions to an MBSE standard, controlling the $\mathrm{CM}$ of a fleet of a single series of aircraft in varying states of engineering change incorporations will be important. If the model created for the MBSE SEMP is not an accurate representation of the current configuration of 130 aircraft with varying configurations, new engineering changes may not work for some of the different aircraft configurations. An example from the author's experience was the release of a new aircraft mission computer for a different series of rotary wing aircraft. When the new mission computers were installed on aircraft with older versions of the multi-function displays, to include older software versions, the mission computers could not communicate with the multi-function displays nor communicate with the aircraft computer. This effectively grounded the aircraft until other aircraft components could be replaced to enable the use of the new mission computers.

\section{Significance for Engineering Changes}

This work is significant regarding the application of MBSE to complex systems that have a long service life and are subject to many engineering changes. Long production timelines that include an increasing number of reliability and capability improvements could result in the last aircraft delivered being very different from the first aircraft delivered. In MBSE, the model generally represents the system in an abstraction. The abstraction suppresses details not of 
interest yet but can bring a precision used to predict the behavior of the system after a change has been implemented (Dickerson \& Mavris, 2013). The effectivity of MBSE could be brought into question when at least $130 \mathrm{MV}-22$ aircraft do not have the same configuration as the model built according to the requirements document from the current SEMP. This variation has cost implications for acquisition efforts, engineering changes, and logistics plans, specifically with supply posturing for change implementation to aircraft with varying configurations (Eckstein, 2017).

\section{Literature Review}

\section{Traditional Systems Engineering}

Systems engineering is focused on the holistic development of a system to meet stakeholder requirements over a useful life (Cook \& Ferris, 2007). Traditional systems engineering relies on text documentation, called artifacts, that are maintained by the systems engineers and updated as requirements change (Madni \& Sievers, 2018). An issue that has emerged is the problem of managing complex systems using traditional systems engineering techniques. Madni and Sievers (2018) noted that as a system becomes more complex with increased workloads on the engineers, the required documentation becomes inconsistent and incomplete. A further problem with a text document centered methodology is the inherent risk of misunderstandings of the requirements. If terminology differences exist between different engineering disciplines, a written requirement may be misinterpreted that could result in the functionality of a component that was never intended or could be incompatible with the current configuration. 


\section{Model Based Systems Engineering}

A shift in systems engineering is occurring because system complexity is becoming increasingly difficult to handle in many industries using document-centered approaches. Critical information and the management of interfaces increasingly face risks of being overlooked because of the amount of time engineers are gathering information and creating reports (Madni \& Sievers, 2018). MBSE seeks to alleviate some difficulties in transmitting information clearly, especially the needs of the end-user and other stakeholders involved in the development of the system (Madni \& Sievers, 2018).

MBSE is not yet standardized internationally, lending to broad interpretations of what the concept is based in part on the lack of comprehensive research into MBSE (Huldt \& Stenius, 2019). In MBSE, the model is the focal point for the activities of conducting systems engineering and for managing the data created as such. The focus is taken from documenting the requirements. However, the elimination of documentation is not the goal of MBSE; the model is used in the generation and validation of the information that generates artifacts such as documentation (Huldt \& Stenius, 2019).

\section{Configuration Management}

Ali and Kidd (2014) define configuration management as “...a management activity that manages the definition of a product, system or process from its earlier definition all the way through the lifecycle" (p. 508). In essence, it defines what the product is and controls the changes to that definition (Burgess, McKee, \& Kidd, 2005). Like traditional systems engineering, configuration management is dependent on documentation and will only be as robust as the documentation provided to the process. However, Burgess et al. (2005) found that the aerospace industry should improve their configuration management practices even though there are 
challenges with product lifecycles that can be 50 years or longer, making configuration management a necessary part of product development and management.

Capabilities of MBSE may be able to simplify configuration management issues (Madni \& Sievers, 2018). Ali and Kidd (2014) found barriers to the successful implementation of configuration management, preventing the process from achieving the desired goals of controlling the product definition, and recording the changes. Nineteen barriers in the groups of managerial and organizational barriers, implementation barriers, and planning and process barriers were identified with many of these barriers being more prevalent in the private aerospace industry rather than in the defense aerospace industry (Ali \& Kidd, 2014).

\section{System of Systems}

There is not much of a conforming definition of the characteristics of a system of systems. There are diverse attempts at creating a concise definition ranging from using characteristics or using taxonomies (Nielsen, Larsen, Fitzgerald, Woodcock, \& Peleska, 2015). Under the idea of defining a system of systems utilizing characteristics, the acronym OMGEE is used. This acronym lists the characteristics of a system of systems as operationally independent $(\mathrm{O})$, managerially independent $(\mathrm{M})$, geographically distributed $(\mathrm{G})$, evolutionarily developed (E), and emergent behavior (E). A second way to define the characteristics is by using the acronym ABCDE; autonomy, belonging, connectivity, diversity, and emerging (Nielsen et al., 2015). For OMGEE, each system operates independently, is managed independent of the other systems across a large geographic area, functionality can be modified, and each system adds synergy to the whole. For ABCDE, each system is independent, collaboratively functioning for a higher purpose with synergy, and able to be adapted to give rise to behaviors that only the system 
of systems can perform (Nielsen et al., 2015). The main idea of a system of systems is the synergistic value that independent systems create when functioning together.

\section{Challenges}

There are challenges in continuing implementation of model-based techniques, specifically with system of systems engineering (Nielsen et al., 2015). Opinions gathered by Nielsen et al. (2015) indicate that some methods and tools are not fully developed to manage the division of functionality between systems in an adaptive infrastructure and challenges still exist in evaluating and measuring how effective the system design is. Huldt and Stenius (2019) found in their study that there is a lack of trained personnel for implementing MBSE, current business processes may hinder the integration of MBSE, and there is a lack of understanding of the value of MBSE in managing complex systems. MBSE is a relatively new technique in systems engineering and may become the standard for systems engineering.

\section{Summary}

Traditional systems engineering and configuration management are both text document focused disciplines that have existed since the end of World War II in the aerospace and defense industries (Ali \& Kidd, 2014; Burgess et al., 2005; Cook \& Ferris, 2007; Madni \& Sievers, 2018). Both have challenges with upkeep and updates to documentation that MBSE may be able to resolve (Madni \& Sievers, 2018). The system of systems idea continues to evolve as industry and academia settle in on the standard definition (Nielsen et al., 2015). Since MBSE and the system of systems ideas are relatively new in the industry, some maturation is predicted to occur as the aerospace industry improves this discipline (Huldt \& Stenius, 2019; Nielsen et al., 2015). 


\section{Method}

The research was conducted by searching for peer-reviewed scholarly articles using the search terms of systems engineering, traditional systems engineering, model-based systems engineering, configuration management, and system of systems. Public information about the state of the V-22 was obtained by searching for news articles through a search engine by using the search terms V-22 configuration management challenges and V-22 configuration management.

Feasibility is the main reason for approaching this work with a case study (Swanborn, 2010). While some information has been released to the public, much of the detail is For Official Use Only (FOUO). A second consideration for the use of a case study is that a real experiment is not feasible (Swanborn, 2010). Different variants of the V-22 exist for the U.S. Marines, for the Navy, for the Air Force and foreign states with cradle to grave management handled by a single program office. Observation of the phenomenon can occur with results compared to past performance, but variables cannot be controlled by the researcher.

\section{Analysis}

The program office for the V-22 currently manages over 70 different variants of the aircraft with a planned consolidation to five aircraft variants. Boeing has been contracted to prove out the remanufacturing instructions with a prototype that is expected to take about a year (Eckstein, 2017). This work should return the V-22 to a standard configuration under greater Configuration Management control.

Under a traditional system engineering program based on documentation over the long developmental phase of the V-22 parallel with production, design modifications to improve capability and reliability complicated the configuration management program. This led to 
variations in mission capability and even to lay out in the aircraft cockpit (Eckstein, 2017). While the changes were managed through the configuration management process, the early production aircraft may not meet the current definition of what makes up a V-22.

MBSE moves away from documentation-based systems engineering to using a model of the system as the primary artifact of the systems engineering process. This should allow for the reuse of modeling artifacts, improvements in quality, and potentially improve communication. This approach can be used from a component model up to the system of systems model (All Partners Access Network, n.d.). However, Configuration Management is still a document-driven discipline that defines what a V-22 is. The challenge for the V-22 program office as systems engineers begin using MBSE is how to maintain the definition of the $\mathrm{V}-22$, how to manage the model, and how to manage the changes in the fleet of aircraft so that the model and definition are representative of the in-service aircraft.

\section{Discussion}

Using the V-22 as an example case study of the transition from a traditional, documentbased systems engineering strategy to an MBSE strategy could illuminate the challenges and issues that could be faced by systems engineers when building a model of an aircraft with up to 70 variants (Eckstein, 2017). This process could be complicated further when the definition of the V-22 is not controlled by the systems engineers but by the configuration managers who are separate from the systems engineers in NAVAIR. In addition, managing the consolidation of 130 aircraft of different configurations into five variants over the course of many years has the potential to complicate any additional reliability and capability improvements to the aircraft, especially if the definition of $\mathrm{V}-22$ has become fuzzy through the creation of a single model in an MBSE framework. 
A second issue to consider is the lack of standardization of an international definition of MBSE or of what a system of systems is. While these emerging methods of definition and management of complex systems seem promising, their application to a decades old complex system undergoing many modifications, with a percentage of the fleet not conforming to the established definition, could lead to further deviations in some blocks of aircraft because of the use of MBSE. The use of a variant of MBSE that drifts away from the internationally recognized definition of MBSE could lose necessary support from the engineering community. This could create a situation where not only is the aircraft variant being controlled by the minority engineering community, but the manner of conducting MBSE becomes managed by a minority as well.

A third issue to consider is the planned number of variants to be managed by the MBSE process in a single program management office. While NAVAIR recognizes the need for an overhaul of the V-22 fleet to bring the entire V-22 fleet to a Block C configuration, what is implied through the application of MBSE is the use of a single model that represents the configuration management definition of what a V-22 is (Eckstein, 2017). However, the customer base that drives five variants of the aircraft complicates the MBSE framework. The use of a single base model could work, but when modifications to the base model have negative effects on the different variants, questions of the validity of the systems engineering strategy could be raised by customers.

A fourth issue to consider is the cooperation between configuration management disciplines and the systems engineering disciplines in developing the MBSE aircraft model. With the configuration management process being handled external to the systems engineering processes in NAVAIR, the potential for misinterpretation of a definition could have a similar 
effect on the application of reliability or capability changes on the aircraft that a single base model could have. Care should be exercised to prevent the configuration management definition of the aircraft from drifting from the model defined by the MBSE process.

\section{Conclusions}

If managed carelessly, the potential for drift between the definition of the aircraft model and the definition of the aircraft through configuration management processes have the potential to create a challenging situation for a program management office. The effect on the aircraft itself could be future reliability and capability modifications working in the MBSE artifact but not performing as designed or required when incorporated into the aircraft.

\section{Recommendations}

The program management office could create five distinct models of the aircraft, one model for each variant requested by each customer, to significantly reduce the issues addressed by Eckstein (2017) of maintaining 70 distinct variants. As the variants drift further away from the basic design, the use of an individual model for each variant could reduce the risk of capability upgrades or needed reliability improvement from not working as designed in one or more variants. This could also reduce complications in the configuration management definition of the aircraft, with five definitions tied to the five separate MBSE artifacts.

As NAVAIR continues to progress with a shift away from document-based systems engineering to MBSE, incorporating changes in the MBSE processes, as it continues to mature through practice inside and outside of the government, should be a benefit. The addition of lessons learned from industry partners and the latest advances in theory and design gained from workshops and symposiums may help optimize and create efficiencies in the use of MBSE. 
The program management office should develop a plan to reconcile the document-based configuration management of the aircraft with the MBSE of the aircraft. While each system has individual strengths and weaknesses, the combination of both styles could lend a synergy for the management of multiple variants. In a sense, using the model to verify the document-based definition and the document-based definition to verify the model could create a check and balance between the two disciplines to provide a complete method of managing a complex system. 


\section{References}

Ali, U., \& Kidd, C. (2014, April). Barriers to effective configuration management application in a project context: An empirical investigation. International Journal of Project Management, 32(3), 508-518. https://doi.org/10.1016/j.ijproman.2013.06.005

All Partners Access Network. (n.d.). Transitioning systems engineering to a model-based discipline. Retrieved from https://community.apan.org/wg/navair-set/navair-mbsecommunity-of-practice/w/resources/21399/transitioning-systems-engineering-to-a-modelbased-discipline/

Boeing. (2018, January 31). Bell Boeing Team to Modify Marine Corps MV-22 Ospreys. Retrieved from https://boeing.mediaroom.com/01-31-2018-Boeing-Bell-Team-Contractto-Upgrade-MV22

Burgess, T. F., McKee, D., \& Kidd, C. (2005). Configuration management in the aerospace industry: A review of industry practice. International Journal of Operations \& Production Management, 25(3), 290-301. https://doi.org/10.1108/01443570510581880

Cook, S. C., \& Ferris, T. L. J. (2007). Re-evaluating systems engineering as a framework for tackling systems issues. Systems Research and Behavioral Science, 24(2), 169-181. https://doi.org/10.1002/sres.822

Dickerson, C. E., \& Mavris, D. (2013). A brief history of models and model based systems engineering and the case for relational orientation. IEEE Systems Journal, 7(4), 581-592. https://doi.org/10.1109/JSYST.2013.2253034

Eckstein, M. (2017, September 14). NAVAIR kicking off V-22 Osprey modernization drive to improve commonality. Retrieved from https://news.usni.org/2017/09/14/navair-kicking-v22-osprey-modernization-drive-improve-commonality 
Huldt, T., \& Stenius, I. (2019, March). State-of-practice survey of model-based systems engineering. Systems Engineering, 22(2), 134-145. https://doi.org/10.1002/sys.21466

Madni, A. M., \& Sievers, M. (2018, May). Model-based systems engineering: Motivation, current status, and research opportunities. Systems Engineering, 21(3), 172-190. https://doi.org/10.1002/sys.21438

Nielsen, C. B., Larsen, P. G., Fitzgerald, J., Woodcock, J., \& Peleska, J. (2015, September). Systems of systems engineering: Basic concepts, model-based techniques, and research directions. ACM Computing Surveys, 48(2). https://doiorg.ezproxy.libproxy.db.erau.edu/10.1145/2794381

Swanborn, P. (2010). Case study research: What, why and how? Thousand Oaks, CA: SAGE Publications. https://doi.org/10.4135/9781526485168

Whyte, J., Stasis, A., \& Lindkvist, C. (2016, February). Managing change in the delivery of complex projects: Configuration management, asset information and 'big data.' International Journal of Project Management, 34(2), 339-351. https://doi.org/10.1016/j.ijproman.2015.02.006 